\title{
Recent Trends and Remaining Limitations in Urban Microclimate Models
}

\author{
Manmeet Singh and Debra F. Laefer* \\ Landscape, and Civil Engineering University, College Dublin Phillips Building, School of Architecture, Room G25 \\ Belfield Dublin 4, Ireland
}

\begin{abstract}
Problems such as natural ventilation, pollutant dispersion, changes in wind environments, and urban heat islands are gaining increasing prominence in both public concern and research. In response, urban microclimate modelling researchers are continually striving to develop new strategies to rapidly and inexpensively generate more accurate results. Numerical modelling is a common way to address these concerns. However, to generate realistic results requires significant investment in model creation, especially with respect to the detail to which a model is populated. This paper provides an overview about this and other recent trends within the research community by considering nearly 100 recent papers. Findings show that despite more computational capacity there has not been a major trend towards increasing the model complexity to obtain more realistic results.
\end{abstract}

Keywords: Air quality, comprehensive turbulent aerosol dynamics and gas chemistry, computational fluid dynamics, environmental justice, microclimate, perceptual fidelity, urban heat island, wind environment.

\section{INTRODUCTION}

Due to continuing changes in land-use practices, rapid urbanization, and heightened awareness about environmental justice, concerns about environmental modelling continue to rise. For urban areas the following microclimates topics are of particular interest:

- Wind flow alteration caused by construction or demolition in the physical environment

- Air quality deterioration affiliated with contaminant transport or pollutant dispersion

- Heat distribution changes related to modifications in land usage

To control wind flow, mitigate air quality deterioration, and limit unintentional temperature changes, several strategies are being undertaken. These include promoting vegetation growth and natural ventilation, reducing traffic to decrease dispersion of ultrafine particles (UFPs), and minimizing energy consumption. To predict the effectiveness of such changes depends upon the quality of available tools to model these phenomena. Such tools require the correct governing equations and boundary conditions and implementation of appropriate numerical algorithms. Arguably they also require a relatively high level of detail of the buildings and the surrounding environment. Yet, anecdotal evidence would indicate that these factors are not regularly being considered. This paper investigates the current state of the art in computational urban microclimate models to try to quantify the

*Address correspondence to this author at the Landscape, and Civil Engineering University, College Dublin Phillips Building, School of Architecture, Room G25 Belfield Dublin 4, Ireland; Tel: 353-1-716-3226;

E-mail: debra.laefer@ucd.ie level of detail being portrayed and to describe a possible new mechanism for populating urban computational models for microclimate modelling.

\section{SCOPE AND METHODOLOGY}

To investigate the current extent to which buildings and their surrounding environments are being modelling numerically, this paper considers three topics: Wind Environment (WE), Air Quality (AQ), and Urban Heat Island (UHI). This is done through the analysis of the work of 223 authors from 22 countries through 56 internationally, peer-reviewed journal papers published from 2010 to 2013 [1-56]. Amongst these were 19 UHI papers exploring vegetation, building energy simulation, urban street characteristics, urban physics, thermal modelling, perpetual fidelity, and thermal comfort [1-19]. An additional 18 papers investigated AQ [20-37], with respect to natural ventilation, dispersion of traffic induced UFPs, contaminant transport, climate change, health in cities, ventilation strategies, micro-environments, and aerosol dynamics. Finally, there were 19 WE papers [38-56] considering the outdoor wind environment, wind flow, cross ventilation, kinetic energy, pollutant dispersion, urban morphology, surface roughness, and vegetation. These 56 papers were considered with respect to 40 earlier papers (published from 2005 to 2010) [57-96] that were previously considered by Laefer and Anwar [97] (Fig. 1).

The percentage of papers that employed numerical modelling (as opposed to use of wind tunnels or field measurements) was similar in each study (85\%). In the current study, numerical modelling was used in $94 \%$ of AQ papers, $89 \%$ of WE papers, and $72 \%$ of UHI papers. So despite arguably ever improving computing capabilities (e.g. being more userfriendly, reliable, and economical, as well as having enhanced visualization and virtual modelling options), numeri- 


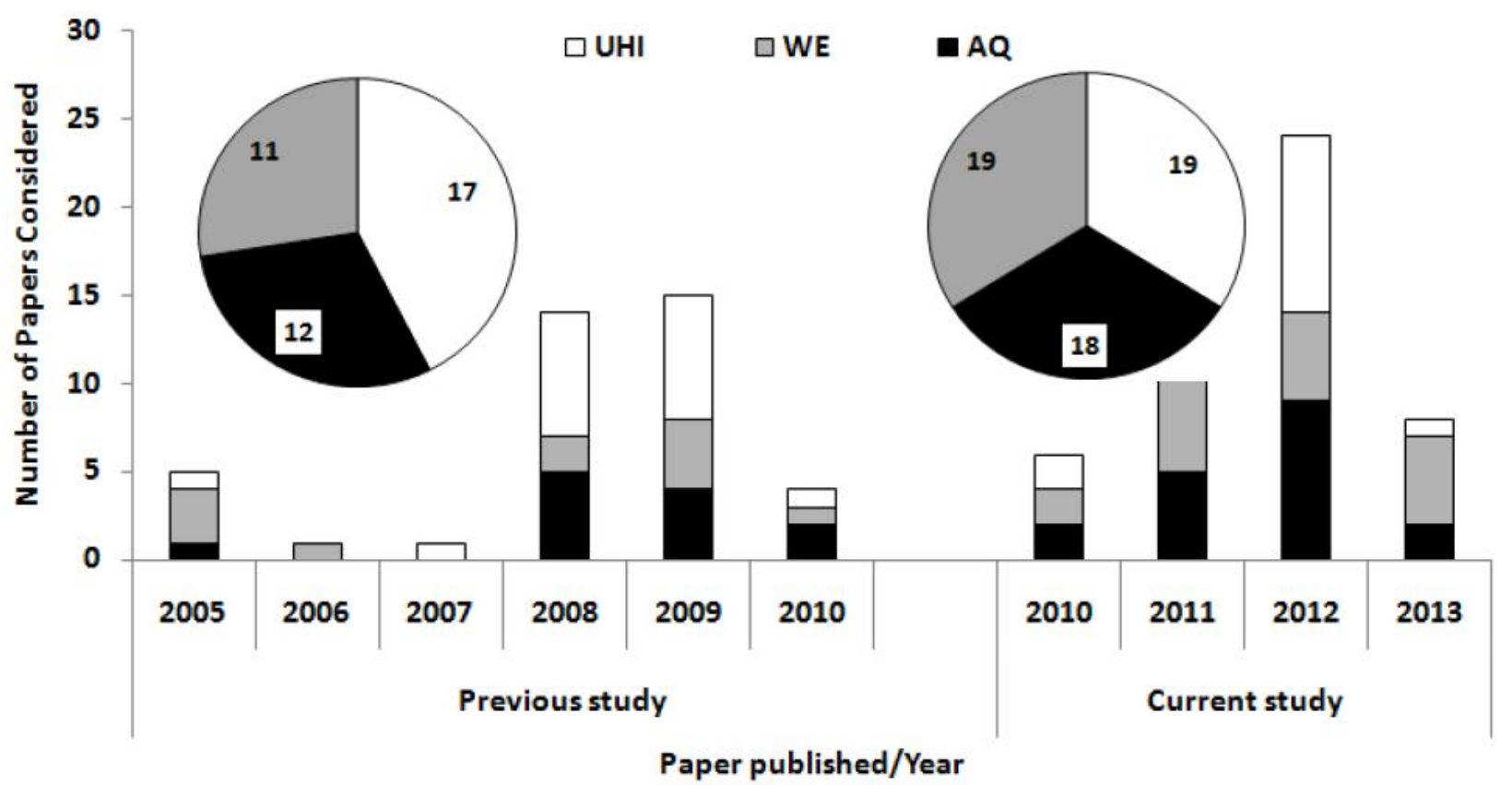

Fig. (1). Number of papers considered per year and papers per category in each study.

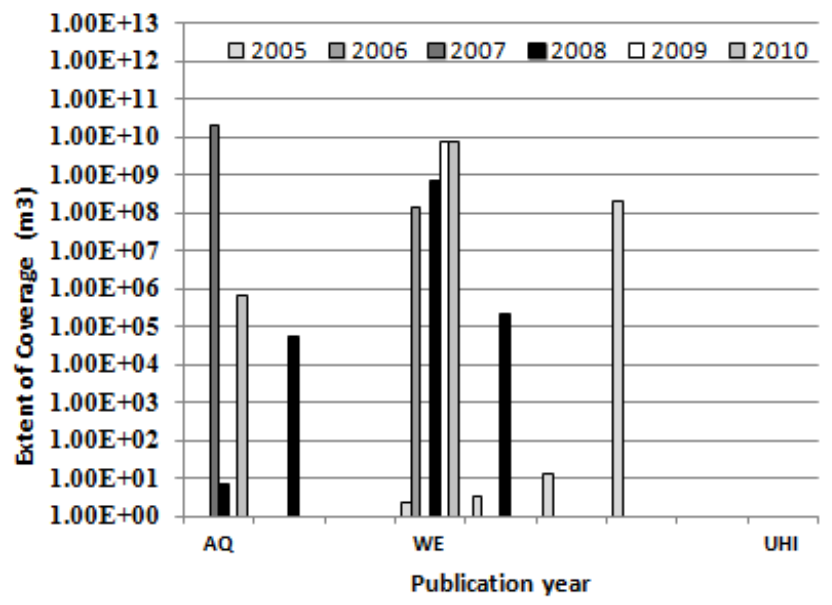

(a) Previous study

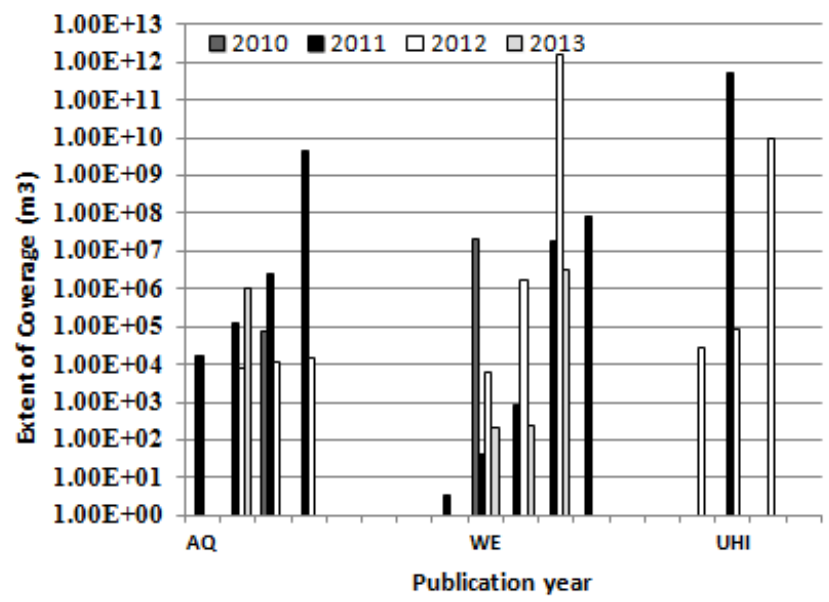

(b) Current study

Fig. (2). Extent of coverage.

cal modelling has not fully displaced physical or analytical modelling. To investigate these and other trends, this paper considers the following topics: the physical representation, the computational representation (when applicable), and the software and algorithms in use.

\section{PHYSICAL REPRESENTATION}

The physical representation involves the model's coverage area, scale, aspect ratio, quantity of included buildings, use of an actual or hypothetical site, and dimension [threedimensional (3D) versus two-dimensional (2D)], as well as feature set selection for model inclusion.

The study area varied from the micro-scale $\left(0.1-10 \mathrm{~km}^{2}\right)$ to the macro-scale $\left(>10,0000 \mathrm{~km}^{2}\right)$ (Fig. 2). One change from the early work is that most current UHI investigations consider the effects of urban areas on nearby suburban areas; previously the geographic extent was not considerd explicitly in UHI modelling.

In the 2010 to 2013 papers, the study area composition ranged from a single building to an entire town. While examples of multi-building inclusion continued, (Fig. 3) depicts a clear trend to include fewer buildings (all 2012 papers included only a single building). What did not change significantly was the use of real locations, as opposed to hypothetical ones (64\% in the new research papers, as opposed to $60 \%$ in papers from 2005 to 2010). The aspect ratio (building height versus street width) varied from 0.125 [46] to 1.25 [34]. While the scale varied from 1:1 to $1: 5000$, the mean scale was 777.87 (with a standard deviation of 1718.16). This was slightly smaller than the 1:1000 in the earlier group of papers [97]. 


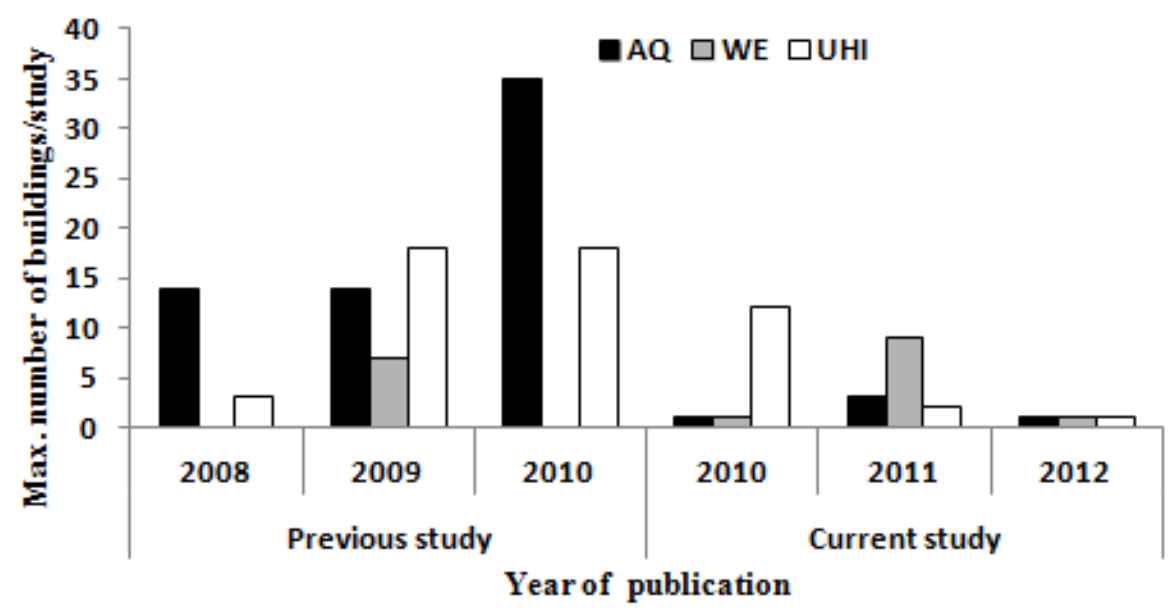

Fig. (3). Number of buildings per study.

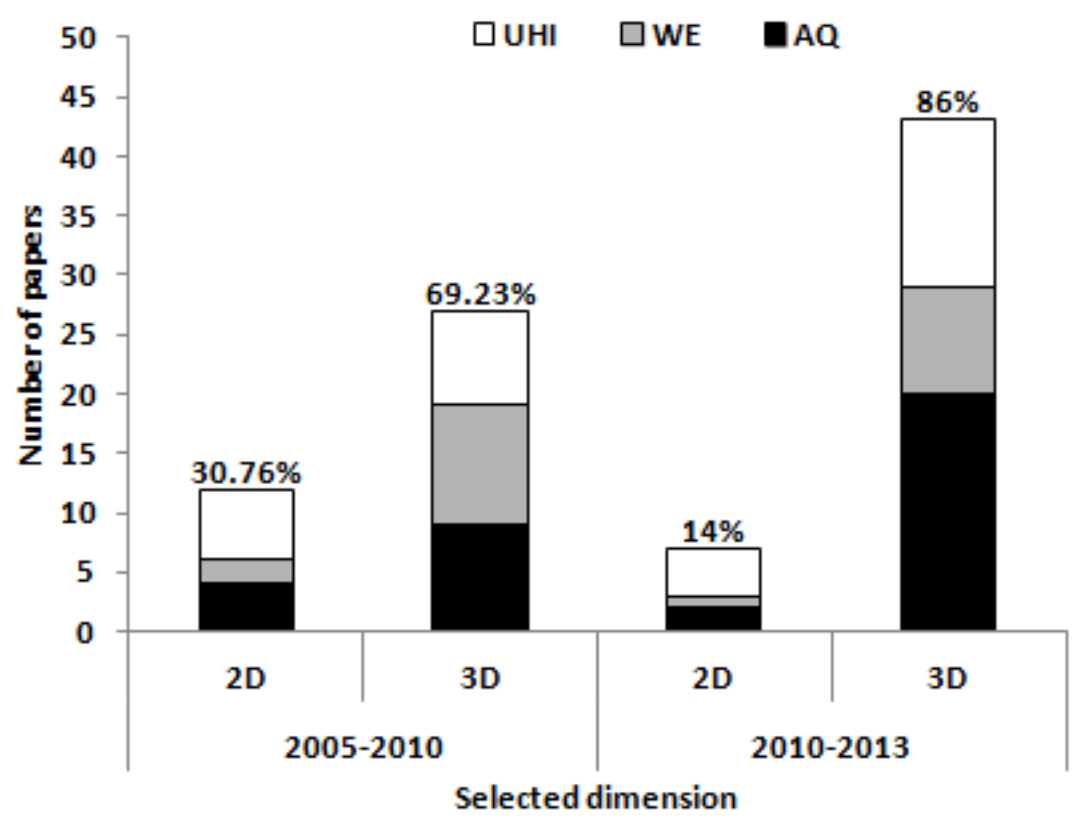

Fig. (4). Selected dimension.

Fig. (4) depicts a growing trend in using a 3D domain versus a $2 \mathrm{D}$ one $(86 \%$ vs. $69 \%)$. Arguably a 3D domain generates more accurate results, despite being computationally more complex and more expensive to populate, with respect to depicting the geometry of the environment. The trend may also be indicative of the increasing availability of 3D remote sensing data with better vertical resolution [98], even though such datasets are only collections of randomly distributed 3D points and do not explicitly contain topological, shape, or size information of the geographical features.

A topic of high interest is the level of detailed included in the models, as that level can impact the output quality, as shown by Li [48], who investigated medium rise buildings with and without balconies for predicting mean wind pressure distribution on windward and leeward surfaces. While the inclusion of such elements has grown significantly (from $0.5 \%$ to $10.7 \%$ ), the overall level remains modest, and many features of the built environment such as footpaths, curbs, and steps have never been considered (Table 1). A similar increased level of inclusion occurred for vegetation (from $1.2 \%$ to $14.8 \%$ ) or building disposition (only [22]), despite natural ventilation being one of the most fundamental way to reduce building energy usage $[4,34]$. Another advance is the increased inclusion of vehicle emissions $(0.2 \% \mathrm{vs} .8 .51 \%)$ to better predict turbulent transport phenomena of air-borne pollutants in built-up areas. So while the overall trends are to increase the realism in the modelling, the adoption levels remain extremely low.

\section{THE COMPUTATIONAL REPRESENTATION}

Irrespective of specific content choices, the computational representation of a micro-climate model involves significant grid-related information (e.g. geometric shape and 
Table 1. Details of modelled elements (shown as a percentage of the papers considered).

\begin{tabular}{|c|c|c|}
\hline Modelled Elements & 40 Papers (2005-2010) & 56 Papers (2010-2013) \\
\hline \hline Vegetation & $1.2 \%$ & NIM \\
\hline Signage & NIM & NIM \\
\hline Street Furniture & NIM & NIM \\
\hline Steps & NIM & $2.1 \%$ \\
\hline Curbs & NIM & NIM \\
\hline Footpath & $0.5 \%$ & $6.3 \%$ \\
\hline Texture & $1 \%$ & $2.1 \%$ \\
\hline Setbacks & $0.2 \%$ & $10.7 \%$ \\
\hline Balconies & NIM & $2.1 \%$ \\
\hline Other Decorative Elements & $0.5 \%$ & $8.51 \%$ \\
\hline Windows & $0.2 \%$ & $0.2 \%$ \\
\hline Vehicles Emissions & & \\
\hline
\end{tabular}

NIM $^{*}$ - Not included in model

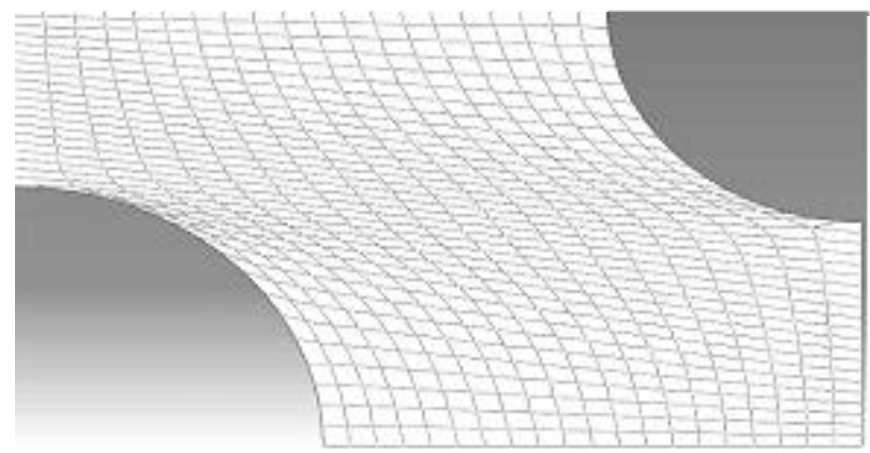

(a) Structured

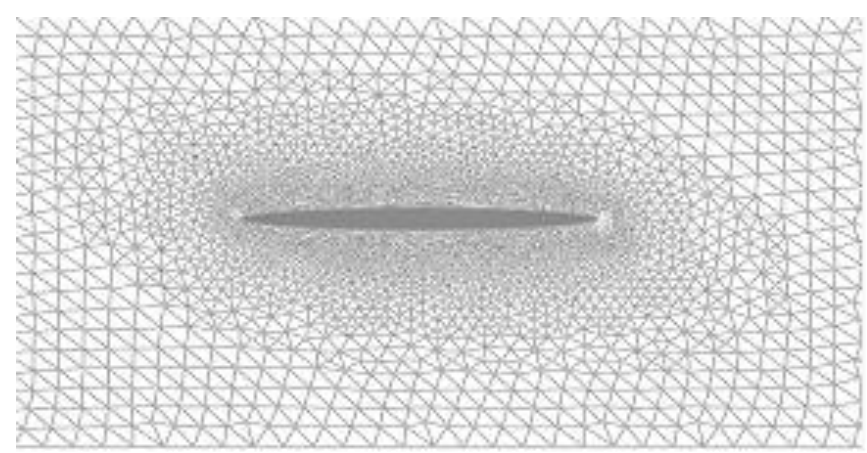

(b) Unstructured

Fig. (5). Geometry of elements.

types, dimensionality, generation technique and population strategy, as well as convergence criteria).

A grid is the arrangement of discrete points/elements over the flow field. Grid generation is the determination of the proper grid for the flow around a given geometric shape. Grids are considered either structured (Fig. 5a) or unstructured (Fig. 5b). Structured grids are generally composed of a regular arrangement of quadrilateral (2D) or hexahedral (3D) elements, while unstructured grids often use triangular (2D) or tetrahedral (3D) elements and can be created automatically for almost any geometry by means of tessellation [99]. While there was no dominance in micro-climate modelling for structured versus unstructured grids, a strong preference (almost 3 to 1) was apparent for the use of 3D elements over 2D elements, despite the related need for more complex calculations for the 3D elements (Table 2).

Generally, one of two different grid generation techniques is applied: (1) the body-fitted or conforming method, or (2) the immersed-boundary method. The most common is the body-fitted method, where the external mesh face conforms to the surfaces [i.e. the external mesh face matches the surface (body surface and/or external surface) (Fig. 6a)]. Usually, a body conforming grid is used for computing the flow around an arbitrary body. This approach requires coordinate transformations and/or complex grid generation. If the body-fitted method is applied to moving bodies, a new mesh must be generated for each time step, which requires significant computing time.

An alternative is the immersed body method (also known as the embedded mesh Cartesian method) (Fig. 6b). The main idea is to place bodies inside the flow region within a large mesh. In this method, the external mesh surface does not fully match the body surface. Hence, the mesh does not need to move. The distinguishing feature of the immersed boundary method is that the entire simulation can be conducted on a Cartesian grid. In such cases, the solid boundary 
Table 2. Selection of numerical elements used in studies.

\begin{tabular}{|c|c|c|c|}
\hline Element Type & Freq. of Usage for Group 1 Papers 2005-2010 & Freq. of Usage for Group 2 Papers 2010-2013 & Dimension \\
\hline \hline Hexahedral & 3 & 6 & 3 \\
\hline Tetrahedral & 2 & 3 & $3 \mathrm{D}$ \\
\hline Prismatic & 1 & 0 & $3 \mathrm{D}$ \\
\hline Irregular & 2 & $3 \mathrm{D}$ & $2 \mathrm{D}$ \\
\hline Triangular & 3 & 2 & $2 \mathrm{D}$ \\
\hline Quadrilateral & 1 & $2 \mathrm{D}$ \\
\hline Rectangular & 1 & 39 & 2 \\
\hline
\end{tabular}

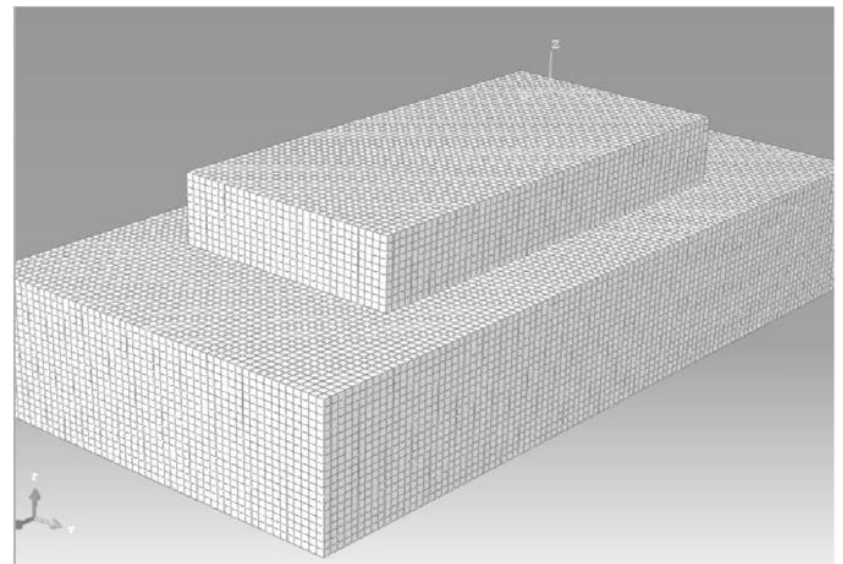

(a) Body-fitted grid

Fig. (6). Grid generation techniques.

cuts through the grid. Because the grid does not conform to the solid boundary, imposing boundary conditions requires modifying the governing equations in the vicinity of the boundary. This method applies to the treatment of problems with (1) dirty geometry, (2) moving bodies with thin gaps, and (3) those with laminar flow [99]. While the immersedboundary method has the advantage of being simple, thereby minimizing CPU and memory requirements without compromising the accuracy, it still exhibits many shortcomings, as identified in references [99-101].

- Approximations occur at boundaries.

- Near the boundaries, the embedding boundary conditions need to be applied, which may reduce the local order of approximation for the partial differential equations.

- Mesh adaptivity is essential for most cases.

- Considerable time is required to build the proper boundary conditions for elements close to the surface or inside bodies for moving boundaries.

- Obtaining the information required to transfer forces back to the structural surface can be time consuming for fluid-structure interaction problems.

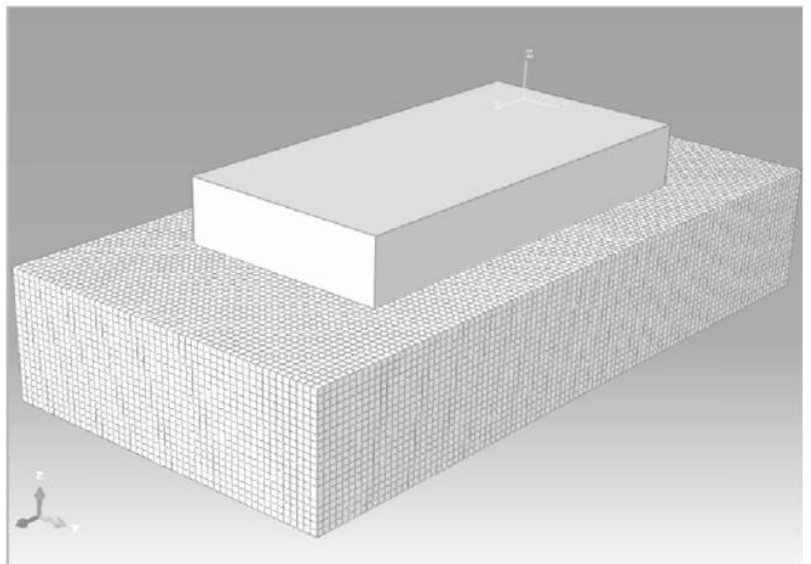

(b) Immersed boundary grid

Irrespective of element geometry, element type, or grid generation type, several user-defined inputs are needed. One is the mesh density. The number of grids required for a mesh depends upon the complexity of the object. The inclusion of more grids generates more accurate results but adversely increases the computer runtime. In the papers considered, grid population varied from $1.00 \mathrm{E}+05$ to +09 , without any discernible trends between the data sets (Fig. 7).

Another user-defined parameter relates to convergence. The convergence level can control the processing duration. Higher values may decrease runtimes but may lead to possible instabilities. Conversely, lower values may further increase stability at the expense of longer runtimes. Numerical methods used to solve the equations for fluid flow and heat transfer most often employ multiple iterations, thus requiring convergence criteria. In many cases, iterative methods are supplemented with relaxation techniques. For example, overrelaxation is often used to accelerate the convergence of pressure-velocity iteration methods, which are needed to satisfy an incompressible flow condition. Under-relaxation is sometimes used to achieve numerically stable results when all the flow equations are implicitly coupled. Selecting proper relaxation and convergence criteria can be difficult. The convergence criteria depends on the specifics of the 


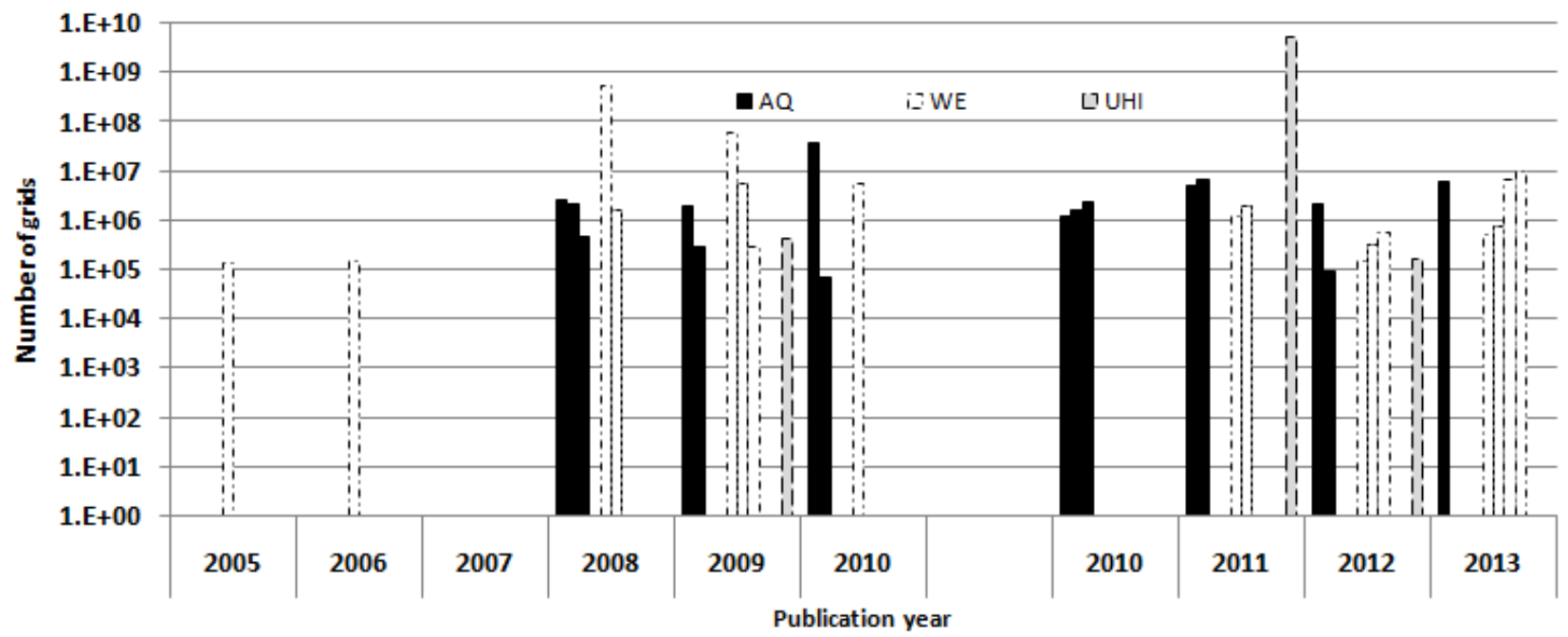

Fig. (7). Number of grids employed per study.

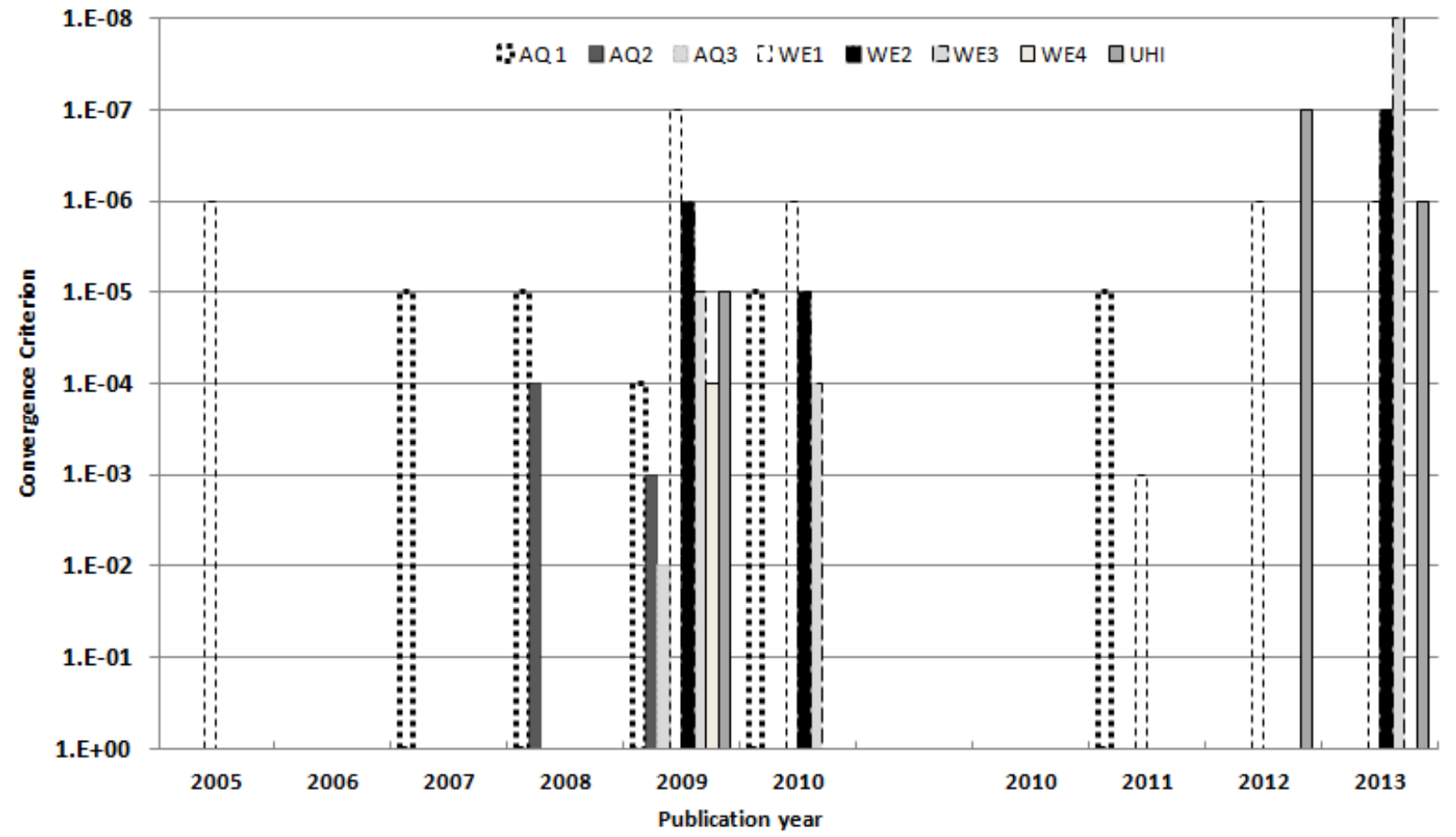

Fig. (8). Convergence criterion.

problem being solved, which may change during the evaluation of a problem. There are no universal guidelines for selecting criteria because they depend not only on the physical processes but also on the detail of the numerical formulation. Across the 96 papers, the convergence criterion varied from IE-4 to IE-7, thereby showing no discernible trends.

\section{MODEL AND SOFTWARE SELECTION}

The final topic area for consideration in this paper relates to model and software selection, which depends upon the problem's complexity level, nature, and required accuracy of the results, as well as the project's resources. As shown in (Fig. 8), the Reynolds Averaged Navier-Stokes (RANS) approach forms the basis of a large number of the implemented models. RANS can address all scales of turbulence, is considered easy to implement, and is computationally inexpensive. Thus, its popularity persists despite its poor performance in cases of large adverse pressure gradients and its restriction to usage in only fully developed turbulent and nonseparated flows [102]. The next most popular choice is the large eddy simulation method (LES). LES is a filtered 


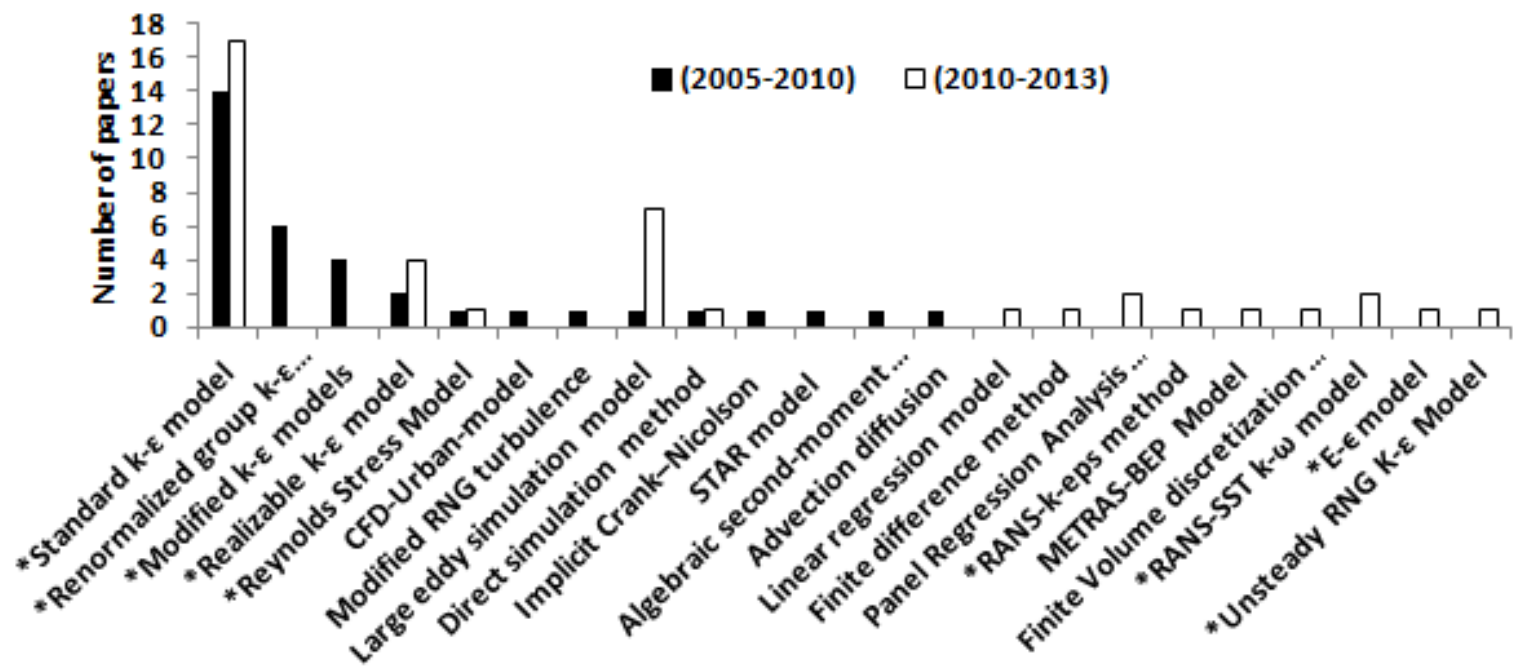

Fig. (9). Implemented models ( $*$ denotes a RANS-based model).

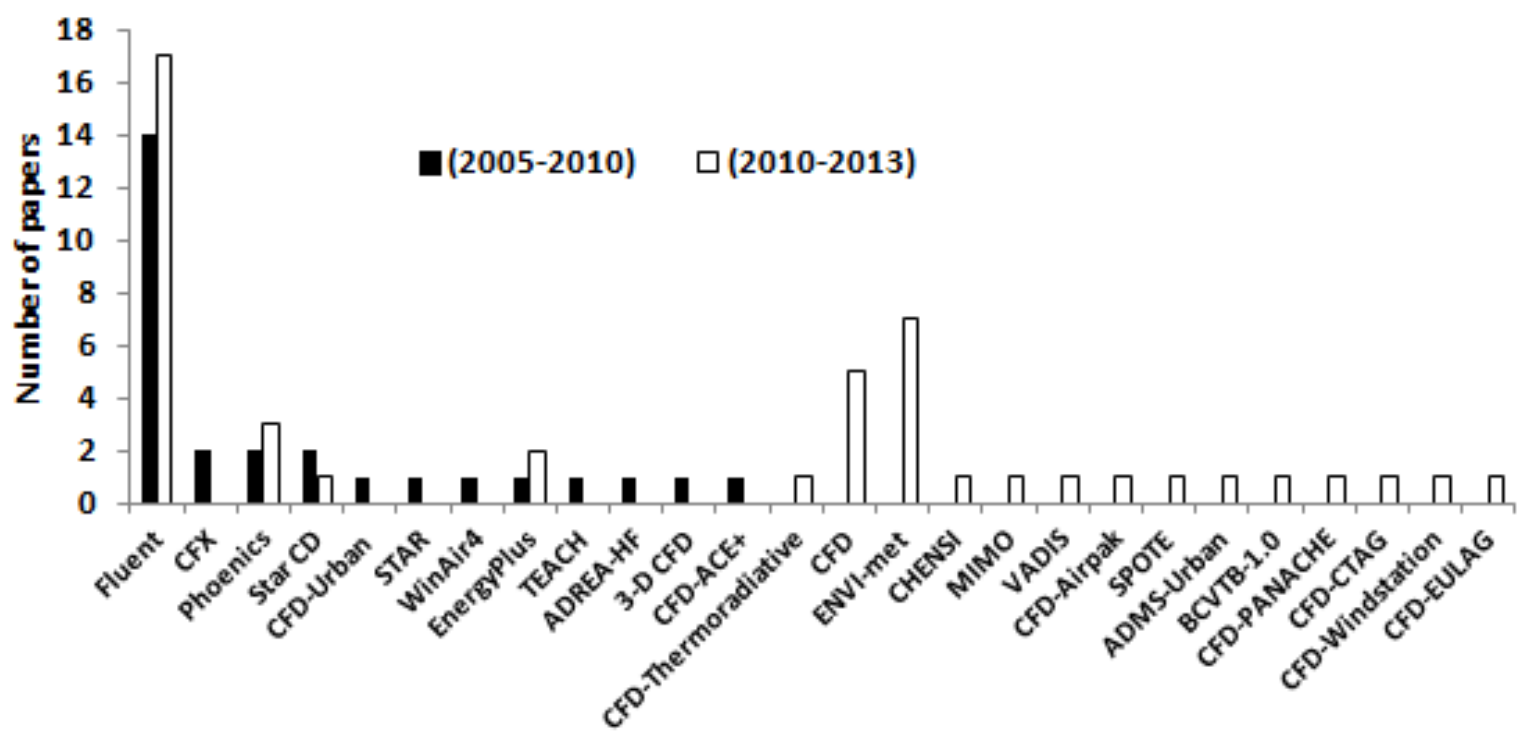

Fig. (10). Selected software.

version of the Navier-Stokes Equations, along with another equation to represent small-scale turbulence. Although more computationally expensive, LES produces more accurate and reliable results, because it resolves the turbulent mixing process in the flow field [53]. Over the past three years, LES has gained in popularity, while usage of the renormalized and modified $\mathrm{k}-\varepsilon$ models has lessened across the entire study set (Fig. 9). The vast majority of specific models were only used once indicating a continued amount of significant development in this area.

Amongst the available commercial software, FLUENT dominates usage (Fig. 10) and is the CFD solver of choice for complex flows ranging from incompressible (low subsonic) and mildly compressible (transonic) ones to highly compressible (supersonic and hypersonic) flows. By providing multiple choices for solver options. FLUENT is applicable to a wide range of engineering problems both laminar and turbulent, for various heat transfer modes, chemical reactions, and multi-phase flows. Notably, there is a growing trend to use ENVI-met: a 3D, numerical microclimate model mainly for air quality that uses a Eulerian approach for calculation of mass, momentum, and an energy budget [34]. ENVI-met is based on a RANS equations, with a nonhydrostatic, micro-scale, obstacle-resolving model and advanced parameterizations for simulation of surface-plant-air interactions in urban environments [103]. ENVI-met provides both spatial resolution $(0.5-10 \mathrm{~m})$ and temporal variation (finest $10 \mathrm{~s}$ resolution) for an urban boundary layer climate. Additionally, ENVI-met has features not commonly available in other CFD dispersion codes (e.g. a detailed microclimate module and a vegetation module). The required input includes meteorological data, emissions, and domain characteristics [32].

\section{NEW DEVELOPMENTS}

Two other new developments were noted that may have a large impact on future modelling. The first was the usage of 


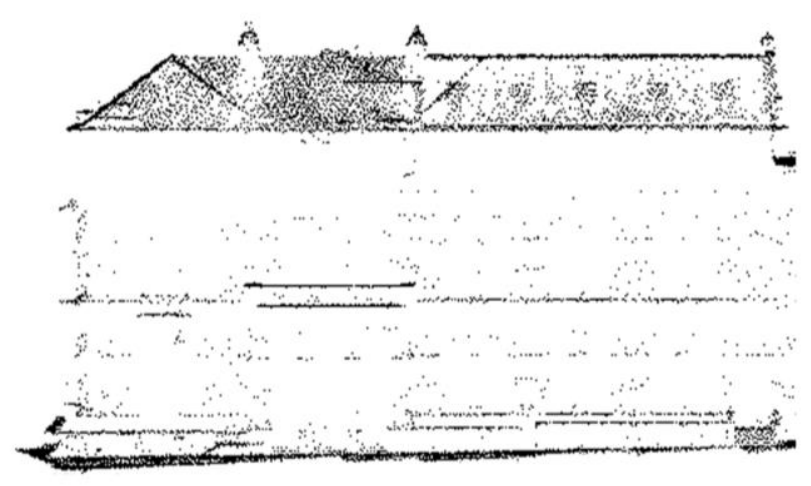

a) Single pass aerial laser scan

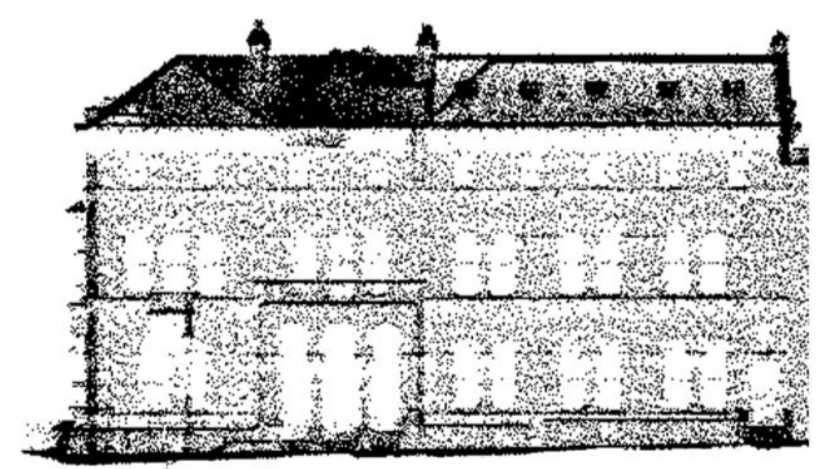

b) Multi-pass aerial laser scan

Fig. (11). Example of current vertical façade data density from aerial laser scanning.

Comprehensive Turbulent Aerosol dynamics and Gas chemistry (CTAG), also called CFD-Vehicle Induced Turbulence (VIT) or CFD-Road Induced Turbulence (RIT). CTAG is a computational fluid dynamics based, turbulent-reaction, flow model to estimate the spatial and temporal impacts of multiple air pollutants from traffic-related emissions for people living near major roads. The approach explicitly couples the major turbulent mixing processes VIT/RIT and atmospheric boundary layer turbulence) with gas-phase chemistry and aerosol dynamics. Aerosol dynamic processes such as nucleation, coagulation, condensation, and evaporation are coupled with turbulent mixing to govern the evolution of exhaust particles. Gas phase chemical reactions also couple with turbulent mixing [36]. A novel multi-scale structure is created to advance the capability of simulating the evolution of UFP's from vehicular tailpipes to near road environment. A multiple scale is implemented in the CTAG model to characterize the micro-environmental air quality near highways. The authors of reference [35] note that CTAG is still computationally expensive compared to parameterized dispersion models, although specific figures were not provided.

The second trend is perceptual fidelity, the idea of introducing sound to reproduce the physical stimuli in microclimatic and multisensory urban environments. Arguably, the main focus to date on visual aspects restricts understanding, since multisensory ambiances are significant $[102,104]$. Namely, the concept of sonic effect describes the interaction between (1) the physical sound environment, (2) the sound milieu of a socio-cultural community, and (3) the "internal soundscape" of each individual.

\section{DISCUSSION}

While more CFD models are including a greater level of detail, there is also a trend to include less of the surrounding structures. One possible explanation is that the extra effort being invested in representing the details of the main structure is consuming resources that are not available for the creation of nearby geometries. If this is the case, one possible solution is the use of aerial laser scanning or other remote sensing technology to represent some or all of the surrounding area. There are however several challenges to this.
While alternative flight paths with multiple overlaps, such as those proposed by Hinks et al. [98] can greatly improve the vertical resolution of data capture (Fig. 11a vs. 11b), and direct conversion methods are available to transform the points into an appropriate solid model [105], approaches for segmentation (Fig. 12) and automated feature identification (two required tasks that provide the path between the data capture and the computational model) are not sufficiently robust at a city-scale. Consequently the resulting geometries will not be very accurate without significant manual intervention. However, given the current trend to excluding nearby built elements can be offset by the inclusion of these less than perfect automated models.

\section{CONCLUSION}

In this survey of nearly 100 micro-climate modelling papers over the past eight years several trends were noted:

1. The inclusion of fewer buildings (and often only one building), but with a higher level of detail (especially vegetation and vehicle emissions), at a $25 \%$ smaller scale, and with a greater propensity of using more actual sites (as opposed to hypothetical locations).

2. A greater usage of three-dimensional aspects (as opposed to two-dimensional ones) in both the domain and in the choice of elements.

3. A growing trend for the Large Eddy Simulation method and ENVI-met software, despite a continuing dominance of RANS-based methods and the software Fluent.

While the latter two trends represent clear advances in the field, the first is not definitively so and raises the question as to why the higher detailing of buildings seems to be in parallel with the exclusion of surrounding structures. Certainly, the justification for omitting surrounding structures is regularly excluded from recently published literature. What appears to be missing is a clear set of guidelines for research as to the extent of surrounding obstacles that should be included for the adequate modelling of the three cases of wind, urban heat, and pollution dispersion. 


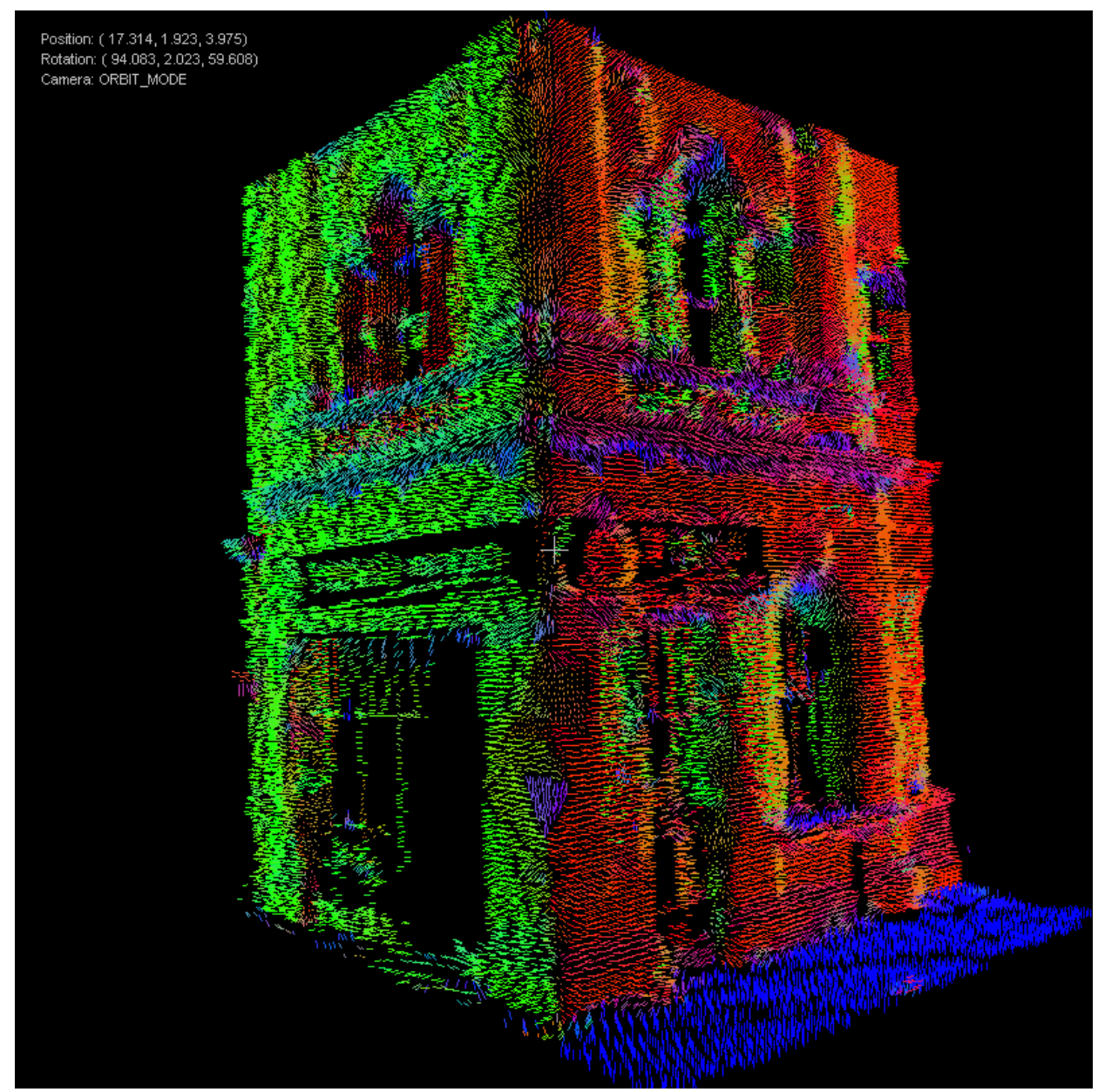

Fig. (12). Example of segmentation of aerial laser scanning data for subsequent use in a computational model.

\section{CONFLICT OF INTEREST}

The authors confirm that this article content has no conflict of interest.

\section{ACKNOWLEDGEMENTS}

Declared none.

\section{REFERENCES}

[1] Allegrini J, Dorer V, Carmeliet J. Influence of the urban microclimate in street canyons on the energy demand for space cooling and heating of buildings. Energy Build 2012; 55: 823-32.

[2] Ashie Y, Kono T. Urban-scale CFD analysis in support of a climate-sensitive design for the Tokyo Bay area. Intl J Climatol 2011; 31(2): 174-88.

[3] Bouyer J, Inard C, Musy M. Microclimatic coupling as a solution to improve building energy simulation in an urban context. Energy Build 2011; 43(7): 1549-59.

[4] Boukhabla M, Djamel A. Impact of vegetation on thermal conditions outside, thermal modeling of urban microclimate, case study: the street of the Republic, Biskra. Energy Procedia 2012; 18: 73-84.

[5] Benzerzour M, Masson V, Groleau D, Lemonsu A. Simulation of the urban climate variations in connection with the transformations of the city of Nantes since the $17^{\text {th }}$ century. Build Environ 2011; 46(8): 1545-57.
[6] Chen L, Ng E. Simulation of the effect of downtown greenery on thermal comfort in subtropical climate using PET index: a case study in Hong Kong. Arch Sci Rev 2012; 1-9.

[7] Defraeye T, Blocken B, Carmeliet J. CFD simulation of heat transfer at surfaces of bluff bodies in turbulent boundary layers: evaluation of a forced-convective temperature wall function for mixed convection. J Wind Eng Ind Aerod 2012; 104-6: 439-46.

[8] Fahmy M, Sharples S. Urban form, thermal comfort and building $\mathrm{CO} 2$ emissions - a numerical analysis in Cairo. Build Services Eng Res Tech 2011; 32(1): 73-84.

[9] Grawe D, Thompson H, Salmond J, Cai X, Schlünzen K Modelling the impact of urbanisation on regional climate in the Greater London area. Intl J Climatol 2012; 33(10): 2388-401.

[10] Heldens W, Esch T, Heiden U. Supporting urban microclimate modelling with airborne hyperspectral data. IEEE International Geoscience and Remote Sensing Symposium 2012; pp. 1598-601.

[11] Heldens W, Heiden U, Esch T, Dech S. Potential of hyperspectral data for urban microclimate analysis. In: Proceedings of Hyperspectral Workshop (ESA SP-683) 2010.

[12] Hu Z, Yu B, Chen Z, Li T, Liu M. Numerical investigation on the urban heat island in an entire city with an urban porous media model. Atmos Environ 2012; 47: 509-18.

[13] Hénon A, Mestayer PG, Lagouarde JP, Voogt JA. An urban neighborhood temperature and energy study from the CAPITOUL experiment with the SOLENE model. Theor Appl Climatol 2012; 110(1-2): 177-96.

[14] Oka M. The influence of urban street characteristics on pedestrian heat comfort levels in Philadelphia. Trans GIS 2011; 15(1): 109-23.

[15] Onishi A, Cao X, Ito T, Shi F, Imura H. Evaluating the potential for urban heat-island mitigation by greening parking lots. Urban For Urban Greening 2010; 9(4): 323-32. 
[16] San Jose R, Perez JL, Gonzalez RM. Sensitivity analysis of two different shadow models implemented into EULAG CFD model: Madrid experiment. Res J Chem Environ 2011; 15(2): 1-8.

[17] Sun Y, Heo Y, Xie H, Tan M, Wu J, Augenbroe G. Uncertainty quantification of microclimate variables in building energy simulation. In: Proceedings of Building Simulation 2011; pp. 242330.

[18] Wong, MS, Nichol JE. Spatial variability of frontal area index and its relationship with urban heat island intensity. Int J Remote Sens 2013; 34(3): 885-96

[19] Yang X, Zhao L, Bruse M, Meng Q. An integrated simulation method for building energy performance assessment in urban environments. Energy Build 2012; 54: 243-51.

[20] Blocken B, Tominaga Y, Stathopoulos T. CFD simulation of micro-scale pollutant dispersion in the built environment. Build Environ 2013; 1-9.

[21] Cao Leo NY, Cao J, Lee S, Zhang Y, Tie X. Numerical simulation of the micro environment in the Han Yang Mausoleum museum. Aerosol Air Quality Res 2012; 12: 544-52.

[22] Cheung James OP, Liu CH. CFD simulations of natural ventilation behaviour in high-rise buildings in regular and staggered arrangements at various spacings. Energy Build 2011; 43(5): 114958.

[23] Choi JI, Edwards JR. Large-eddy simulation of human-induced contaminant transport in room compartments. Indoor Air 2012; 22(1): 77-87.

[24] Corgnati SP, Perino M. CFD application to optimise the ventilation strategy of Senate Room at Palazzo Madama in Turin (Italy). J Cultural Heritage 2013; 14(1): 62-9.

[25] Gallagher J, Gill LW, McNabola A. Numerical modelling of the passive control of air pollution in asymmetrical urban street canyons using refined mesh discretization schemes. Build Environ 2012; 56: 232-40.

[26] Gu ZL, Zhang YW, Cheng Y, Lee SC. Effect of uneven building layout on air flow and pollutant dispersion in non-uniform street canyons. Build Environ 2011; 46(12): 2657-65.

[27] Han M, Chen H, Yuan L, Han G, Li B. CFD analysis on cooling effect on a complex traditional urban area with river wind in summer. IEEE 2011; 3880-3.

[28] Hang J, Li Y, Sandberg M, Buccolieri R, Sabatino SD. The influence of building height variability on pollutant dispersion and pedestrian ventilation in idealized high-rise urban areas. Build Environ 2012; 56: 346-60.

[29] Li Y, Nielsen PV. CFD and ventilation research. Indoor Air 2011; 21(6): 442-53.

[30] Lateb M, Masson C, Stathopoulos T, Bédard C. Numerical simulation of pollutant dispersion around a building complex. Build Environ 2010; 459(8): 1788-98.

[31] Madala S. Micro-scale dispersion of air pollutants over an urban setup in a coastal region. Open J Air Pollution 2012; 1(2): 51-8.

[32] Nikolova I, Janssen S, Vos P, Vrancken K, Mishra V, Berghmans P. Dispersion modelling of traffic induced ultrafine particles in a street canyon in Antwerp, Belgium and comparison with observations. Sci Total Environ 2011; 412: 336-43.

[33] Tominaga Y, Stathopoulos T. Numerical simulation of dispersion around an isolated cubic building: model evaluation of RANS and LES. Build Environ 2010; 45(10): 2231-39.

[34] Wania A, Bruse M, Blond N, Weber C. Analysing the influence of different street vegetation on traffic-induced particle dispersion using microscale simulations. J Environ Manage 2012; 94(1): 91101.

[35] Wang YJ, Nguyen MT, Steffens JT, et al. Modeling multi-scale aerosol dynamics and micro-environmental air quality near a large highway intersection using the CTAG model. Sci Total Environ 2013; 443: 375-86.

[36] Wang YJ, Zhang KM. Coupled turbulence and aerosol dynamics modeling of vehicle exhaust plumes using the CTAG model. Atmos Environ 2012; 59: 284-93.

[37] Yuan C, Ng E. Building porosity for better urban ventilation in high-density cities - a computational parametric study. Build Environ 2012; 50: 176-89.
[38] Abohela I, Hamza N, Dudek S. Effect of roof shape, wind direction, building height and urban configuration on the energy yield and positioning of roof mounted wind turbines. Renew Energ 2013; 50: 1106-18.

[39] Araújo A, Valença D, Asibor I, Rosas C. An approach to simulate wind fields around an urban environment for wind energy application. Environ Fluid Mech 2012; 13(1): 33-50.

[40] Bady M, Kato S, Ishida Y, Huang H, Takahashi T. Application of exceedance probability based on wind kinetic energy to evaluate the pedestrian level wind in dense urban areas. Build Environ 2011; 46(9): 1834-42.

[41] Butler J, Quail F, Irvine I. Comparison of 2nd generation LiDAR wind measurement technique with CFD numerical modelling. EWEA 2012; 1-6.

[42] Chavez M, Hajra B, Stathopoulos T, Bahloul A. Near-field pollutant dispersion in the built environment by CFD and wind tunnel simulations. J Wind Eng Ind Aerod 2011; 99(4): 330-9.

[43] Hong B, Lin B, Hu L, Li S. Study on the impacts of vegetation on wind environment in residential district combined numerical simulation and field experiment. Procedia Environ Sci 2012; 13 1708-17.

[44] Hooff T, Blocken B. CFD evaluation of natural ventilation of indoor environments by the concentration decay method: $\mathrm{CO}_{2}$ gas dispersion from a semi-enclosed stadium. Build Environ 2013; 61: 1-17.

[45] Harlan S, Ruddell D. Climate change and health in cities: impacts of heat and air pollution and potential co-benefits from mitigation and adaptation. Environ Sustain 2011; 3: 126-34.

[46] Jackson A, Villiers E, Campos F, Beyers M, Kastrup J, Bennetsen J. Prediction of pedestrian wind and thermal comfort and pollutant dispersal in an urban environment. $6^{\text {th }}$ open FOAM workshop 2011; $13-4$

[47] Li C, Li X, Su Y, Zhu Y. A new zero-equation turbulence model for micro-scale climate simulation. Build Environ 2012; 47: 24355 .

[48] Li Y. Computational fluid dynamics technology and its application in wind environment analysis. J Urban Technol 2010; 17(3): 67-81.

[49] Montazeri H, Blocken B. CFD simulation of wind-induced pressure coefficients on buildings with and without balconies: validation and sensitivity analysis. Build Environ 2013; 60: 137-149.

[50] Ng E, Yuan C, Chen L, Ren C, Fung J. Improving the wind environment in high-density cities by understanding urban morphology and surface roughness: a study in Hong Kong. Landscape Urban Plan 2011; 101(1): 59-74.

[51] Radhi H, Sharples S, Fikiry F. Will multi-facade systems reduce cooling energy in fully glazed buildings? A scoping study of UAE buildings. Energy Build 2013; 56: 179-88.

[52] Ramponi R, Blocken B. CFD simulation of cross-ventilation flow for different isolated building configurations: validation with wind tunnel measurements and analysis of physical and numerical diffusion effects. J Wind Eng Ind Aerod 2008; 104-106: 408-18.

[53] Roy AK, Bhargava PK. CFD modelling of wind flow around buildings for wind energy conversion. Proceedings of the National Conference on Emerging Trends of Energy Conservation in Buildings held at CSIR-CBRI 2012, 370-9.

[54] Salim M, Cheah S, Chan A. Numerical simulation of dispersion in urban street canyons with avenue-like tree plantings: comparison between RANS and LES. Build Environ 2011; 46(9): 1735-46.

[55] Vardoulakis S, Dimitrova R, Richards K, et al. Numerical model inter-comparison for wind flow and turbulence around single-block buildings. Environ Model Assess 2010; 16(2): 169-81.

[56] Zhang N, Meng Q. Comparative analysis of digital simulation on outdoor wind environments of a middle school. Proceedings of the International Conference on Multimedia Technology 2011; 5326-9.

[57] Agarwal M, Tandon A. Modeling of the urban heat island in the form of mesoscale wind and of its effect on air pollution dispersal. Appl Math Model 2009; 34(9): 2520-30.

[58] Alexandri E, Jones P. Temperature decreases in an urban canyon due to green walls and green roofs in diverse climates. Build Environ 2008; 43(4): 480-93. 
[59] Abuku M, Blocken B, Nore K, Thue JV, Carmeliet J, Roels S. On the validity of numerical wind-driven rain simulation on a rectangular low-rise building under various oblique winds. Build Environ 2008; 44(3): 621-32.

[60] Blocken B, Carmeliet J. Overview of three state-of-the-art winddriven rain assessment models and comparison based on model theory. Build Environ 2009; 45(3): 691-703.

[61] Cheng WC, Liu CH, Leung DYC. On the correlation of air and pollutant exchange for street canyons in combined wind-buoyancydriven flow. Atmos Environ 2009; 43(24): 3682-90.

[62] Carpentieri M, Robins AG. Wind tunnel experiments of flow and dispersion in a real urban area. Proceedings of the $7^{\text {th }}$ International Conference on Urban Climate 2009; pp. 1-4.

[63] Cheng WC, Liu CH, Leung DYC. Computational formulation for the evaluation of street canyon ventilation and pollutant removal performance. Atmos Environ 2008; 42(40): 9041-51.

[64] Coirier WJ, Fricker DM, Furmanczyk M, Kim S. A computational fluid dynamics approach for urban area transport and dispersion modeling. Environ Fluid Mech 2005; 5(5): 443-79.

[65] Gromke C, Buccolieri R, Di SS, Ruck B. Dispersion study in a street canyon with tree planting by means of wind tunnel and numerical investigations-evaluation of CFD data with experimental data. Atmos Environ 2008; 42(37): 8640-50.

[66] He J, Hoyano A, Asawa T. A numerical simulation tool for predicting the impact of outdoor thermal environment on building energy performance. Appl Energ 2009; 86(9): 1596-605.

[67] Hooff TV, Blocken B. Coupled urban wind flow and indoor natural ventilation modelling on a high-resolution grid: a case study for the Amsterdam Arena stadium. Environ Modell Softw 2010; 25(1): 5165.

[68] Hooff TV, Blocken B. On the effect of wind direction and urban surroundings on natural ventilation of a large semi-enclosed stadium. Comput Fluids 2010; 39: 1146-55.

[69] Hua CH, Wang F. Using a CFD approach for the study of streetlevel winds in a built-up area. Build Environ 2005; 40(5): 617-31.

[70] Huang Y, Hu X, Zeng N. Impact of wedge-shaped roofs on airflow and pollutant dispersion inside urban street canyons. Build Environ 2009; 44(12): 2335-47.

[71] Huang JM, Ooka R, Okada A, Omori A, Huang H. The effects of urban heat island mitigation strategies on the outdoor thermal environment in central Tokyo - a numerical simulation. Proceedings of the $7^{\text {th }}$ Asia-Pacific Conference on Wind Engineering 2009; 272-9.

[72] Huang H, Ooka H, Kato S. Urban thermal environment measurements and numerical simulation for an actual complex urban area covering a large district heating and cooling system in summer. Atmos Environ 2005; 39(34): 6362-75.

[73] Kim T, Kim K, Kim BS. A wind tunnel experiment and CFD analysis on airflow performance of enclosed-arcade markets in Korea. Build Environ 2009; 45(5): 1329-38.

[74] Li K, Yu Z. Comparative and combinative study of urban heat island in Wuhan city with remote sensing and CFD simulation. Sensors 2008; 8(10): 6692-703.

[75] Memon RA, Leung DYC, Liu CH. Effects of building aspect ratio and wind speed on air temperatures in urban-like street canyons. Build Environ 2009; 45(1): 176-88.

[76] Meyn SK, Oke TR. Heat fluxes through roofs and their relevance to estimates of urban heat storage. Energy Build 2009; 41(7): 74552.

[77] McNabola A, Broderick BM, Gill LW. A numerical investigation of the impact of low boundary walls on pedestrian exposure to air pollutants in urban street canyons. Sci Total Environ 2008; 407(2): 760-9.

[78] McNabola A, Broderick BM, Gill LW. The impacts of inter-vehicle spacing on in-vehicle air pollution concentrations in idling urban traffic conditions. Transp Res Part D: Transport Environ 2009; 14(8): 567-75.

[79] Neofytou P, Venetsanos AG, Vlachogiannis D, Bartzis JG, Scaperdas A. CFD simulations of the wind environment around an airport terminal building. Environ Modell Softw 2006; 21(4): 520-4.
[80] Oguro M, Morikawa Y, Murakami S, Matsunawa K, Mochidad A, Hayashi H. Development of a wind environment database in Tokyo for a comprehensive assessment system for heat island relaxation measures. J Wind Eng Ind Aerod 2008; 96(10-11): 1591-602.

[81] Oliveria Panao MJN, Goncalves HJP, Ferrao PMC. Numerical analysis of the street canyon thermal conductance to improve urban design and climate. Build Environ 2009; 44(1): 177-87.

[82] Oxizidis S, Dudek AV, Papadopoulos AM. A computational method to assess the impact of urban climate on buildings using modeled climatic data. Energy Build 2008; 40(3): 215-23.

[83] Parra MA, Santiago JL, Martín F, Martilli A, Santamaría JM. A methodology to urban air quality assessment during large time periods of winter using computational fluid dynamic models. Atmos Environ 2010; 44(17): 2089-97.

[84] Priyadarsini R, Hien WN, David CKW. Microclimatic modeling of the urban thermal environment of Singapore to mitigate urban heat island. Sol Energy 2008; 82(8): 727-45.

[85] Szucs A, Moreau S, Allard F. Spectators' aerothermal comfort assessment method in stadia. Build Environ 2007; 42(6): 2227-40.

[86] Sabatino SD, Buccolieri R, Pulvirenti B, Britter RE. Flow and pollutant dispersion in street canyons using FLUENT and ADMS. Urban Environ Model Assess 2008; 13(3): 369-81.

[87] Satoa T, Murakamib S, Ookac R, Yoshidad S. Analysis of regional characteristics of the atmospheric heat balance in the Tokyo metropolitan area in summer. J Wind Eng Ind Aerod 2008; 96(10-1): 1640-54.

[88] Shashua-Bar L, Pearlmutter D, Erell E. The cooling efficiency of urban landscape strategies in a hot dry climate. Landscape Urban Plan 2009; 92(3-4): 179-86.

[89] Short CA, Cook MJ, Woods A. Low energy ventilation and cooling within an urban heat island. Renew Energ 2009; 34(9): 2022-29.

[90] Tewari M, Kusaka H, Chen F, et al. Impact of coupling a microscale computational fluid dynamics model with a mesoscale model on urban scale contaminant transport and dispersion. Atmos Res 2010; 96: 656-64.

[91] Wakes SJ, Maegli T, Dickinson KJ, Hilton MJ. Numerical modelling of wind flow over a complex topography. Environ Modell Softw 2009; 25(2): 237-47.

[92] Wang P, Mu H. Numerical simulation of pollutant flow and dispersion in different street layouts. Int J Environ Stud 2010; 67(2): 15567.

[93] Xiao-min X, Jia-song W, Zhen H. Traffic emission transportation in street canyons. J Hydrodynamics 2008; 21(1): 108-17.

[94] Yassin MF, Kellnerova R, Janour Z. Impact of street intersections on air quality in an urban environment. Atmos Environ 2008; 42(20): 4948-63.

[95] Yoshie R, Mochida A, Tominaga Y, Kataoka H, Yoshikawa M. Cross comparisons of CFD prediction for wind environment at pedestrian level around buildings. Proceedings of the $6^{\text {th }}$ Asia-Pacific Conference on Wind Engineering (APCWE-VI) 2005; 2661-70.

[96] Zhang A, Gao C, Zhang L. Numerical simulation of the wind field around different building arrangements. J Wind Eng Ind Aerod 2005; 93(12): 891-904.

[97] Laefer DF, Anwar M. Review of strategies for the geometric creation and population of urban microclimate models. Open Urban Stud J 2012; 5: 22-31.

[98] Hinks T, Carr H, Laefer DF. Flight optimization algorithms for aerial lidar capture for urban infrastructure model generation. J Comput Civil Eng 2009; 23(6): 330-9.

[99] Löhner R, Cebral JR, Camelli FF, et al. Adaptive embedded and immersed unstructured grid techniques. Comput Method Appl M 2008; 197(25-8): 2173-97.

[100] Mittal R, Iaccarino G. Immersed boundary methods. Annu Rev Fluid Mech 2005; 37(1): 239-61.

[101] Smolarkiewicz P, Piotr K, Sharman R, et al. Building resolving large-eddy simulations and comparison with wind tunnel experiments. J Comput Phys 2007; 227(1): 633-53.

[102] Nikolopoulou M., Steemers K. Thermal comfort and psychological adaptation as a guide for designing urban spaces. Energy Build 2003; 35(1): 95-101. 
[103] Bruse M, Fleer H. Simulating surface--plant--air interactions inside urban environments with a three dimensional numerical model. Environ Modell Softw 1998; 13(3): 373-84.

[104] Vigier T, Moreau G, Siret D, Lescop L. A new concept of perceptual fidelity to augment virtual urban environments with microclimatic ambiances. EDP Sciences 2012; 03002: 1-8.
[105] Hinks T, Carr H, Laefer D, et al. Robust Building Outline Extraction. PTO 56793223; full patent filed 05/2009, international report 11/2010, awarded 10/2013 EP2304688 B1. Granted in UK, The Netherlands, Switzerland, Germany, Austria, France, Ireland, and Luxembourg.

Received: March 18, 2014

Revised: April 22, 2014

Accepted: April 28, 2014

(c) Singh and Laefer; Licensee Bentham Open.

This is an open access article licensed under the terms of the Creative Commons Attribution Non-Commercial License (http://creativecommons.org/licenses/ by-nc/3.0/) which permits unrestricted, non-commercial use, distribution and reproduction in any medium, provided the work is properly cited. 